\title{
OS DICIONÁRIOS COMO FONTE LEXICOGRÁFICA ${ }^{1}$
}

\author{
Dieter Messner
}

Paris-Lodron-Universität Salzburg

Rafael Bluteau publicou a partir de 1712 o Vocabulário Portuguez e Latino que, em grande parte, já foi redigido antes de 1700; nele há duas entradas: uma Santiago, e a outra Compostela:

\begin{tabular}{|c|c|}
\hline Bluteau (1712-1728) & Covarrubias (1611) \\
\hline $\begin{array}{l}\text { Compostella, ou San-Thiago de Galiza. } \\
\text { Cidade, \& Arcebispado de Galiça em } \\
\text { Hespanha. } \\
\text { Covarrubias, curioso investigador de } \\
\text { Etymologias, confessa, que lhe não foy } \\
\text { possível achar a deste nome; \& sospei- } \\
\text { ta, que Compostella se disse de alguma } \\
\text { estrella, que assinalasse o lugar, donde } \\
\text { estava o corpo do Santo Apostolo. [...] } \\
\text { V. San-Tiago. }\end{array}$ & $\begin{array}{l}\text { Compostella }[\ldots] \text { La etimologia de } \\
\text { Compostela no la sé con certidumbre; } \\
\text { pudo haberse dicho de alguna estrella o } \\
\text { cometa, que señalase el lugar donde esta- } \\
\underline{\text { ba el cuerpo santo del Apóstol. }}\end{array}$ \\
\hline $\begin{array}{l}\text { Santiago. Cidade de Hespanha, no Re- } \\
\text { yno de Galliza. Tem Arcebispo, \& Uni- } \\
\text { versidade. } \\
\text { He celebre pelo grande concurso dos pe- } \\
\text { regrinos, que vão visitar na Igreja Metro- } \\
\text { politana o corpo do Apostolo Santiago. } \\
\text { Chama-se por outro nome Compostella, } \\
\text { que segundo alguns he o Brigantium de } \\
\text { Antonino, Dion, \& Osório [...]. V. Com- } \\
\text { postella. }\end{array}$ & $\begin{array}{l}\text { Santiago. Ciudad populosa y memorada } \\
\text { en toda la cristiandad, pues de todas par- } \\
\text { tes della vienen en peregrinación a visitar } \\
\text { el cuerpo del apóstol Santiago }[\ldots] .\end{array}$ \\
\hline
\end{tabular}

1. No ano 1986, com motivo dum colóquio de lexicografia (cfr. Ramón Lorenzo 1988), reunira-se na cidade de Santiago de Compostela um grupo de importantes lexicógrafos das línguas românicas. Alguns, infelizmente, já desapareceram. Para que a memória deles continue, reproduzo uma foto em anexo. 
Bluteau menciona expressis verbis a fonte, o lexicógrafo espanhol Sebastián de Covarrubias Horozco, o autor do Tesoro de la lengua castellana o española, deixando ver um comportamento que muitos lexicógrafos antigos e modernos não mostram tão frequentemente, ocultando as fontes.

Se compararmos as citações sacadas dos dois dicionários, podemos constatar uma semelhança bastante alta. É provável que Bluteau não só tenha copiado a etimologia proposta pelo Covarrubias -ele o confessa-, mas sim também outros troços da microestrutura do modelo espanhol, que sublinhei no texto. E com este exemplo já estamos no centro da minha contribuição.

Fui convidado para tratar dos dicionários como fonte lexicográfica, e concentrar-me em dicionários portugueses, por isso não me vou ocupar de dicionários espanhóis, os quais, ao contrário do que aconteceu com os portugueses, já foram analisados sob este ponto de vista. De cada dicionário espanhol com certa importância já se conhece a genealogia, por exemplo do Universal Vocabulario de Alfonso de Palencia (1490)-dizem- uma fonte foi o Elementarium Doctrinae rudimentum de Papias, do Tesoro de Covarrubias (1611) uma fonte foi o Calepino, etc., etc. (cfr. Azorín Fernández 2000). Não conheço o número exacto de estudos, são muitíssimos, que se fizeram sobre os dicionários que copiavam as várias edições do Diccionario de la lengua española (DRAE). E não só os lexicógrafos espanhóis copiaram o DRAE, mas sim também os autores de dicionários galegos, como mostrou Santamarina, que chamou a atenção sobre a forma como Sobreira copiou o DRAE de 1780: "se se cotexan as papeletas de Sobreira co diccionario da RAE 1780 o asunto resulta case escandaloso" (Santamarina 2003b: 54). E para a língua catalã consta: "El diccionari de l’Academia española serà guia universal dels de la nostra llengua" (Rico / Solà 1995: 127).

A minha presença aqui justifica-se por ser responsável de um projecto de grande envergadura que se chama Dicionário dos dicionários portugueses. Publiquei já 20 volumes, com um total de 12.000 páginas (Messner 1994- ).

Para o espanhol existe uma obra semelhante, o Tesoro lexicográfico 1492-1726, de Samuel Gili Gaya (1947-1957); infelizmente ficou inacabado. Mas teremos dentro de pouco um Nuevo Tesoro, o NTLE, redigido por Manuel Alvar e Lidio Nieto.

Com a ajuda da obra de Gili Gaya foi possível esclarecer a história de palavras espanholas, e a genealogia dos dicionários. Só quero mencionar o exemplo da palavra aferes à que Nebrija atribuíu o significado 'nugae', quer dizer 'coisas sem importância', um significado errado que se conservou em todos os dicionários seguintes, durante mais de dois séculos, até ao ano de 1726. Só o Diccionario de Autoridades corrige este significado. 
Descobrir a genealogia de palavras pode fazer-se agora também para a língua galega com o Diccionario de diccionarios, um CD-Rom editado por Antón Santamarina (2003b). E também já está pronto o Tresor lexicográfic valencià (Guardiola Savall 2006).

O Dicionário dos dicionários portugueses reúne uns 40 dicionários e obras de interesse lexicográfico, publicados entre 1554 e 1858. Comecei, claro, com muitos mais dicionários; mas muitos são cópias de dicionários anteriores, por isso, tirei-os da minha lista actual (cfr. http://www.sbg. ac.at/rom/people/prof/messner/dddport.htm).

As entradas portuguesas do dicionário português-latim de Bento Pereira (1697) foram copiadas, pela maior parte, por um lexicógrafo desconhecido em 1701, para o primeiro dicionário bilingue português-inglês (A. J. 1701), e por Alewyn em 1714, para o primeiro dicionário portuguêsflamengo (Alewyn / Collé 1714).

\begin{tabular}{|c|c|c|}
\hline Pereira (1697) & A.J. (1701) & Alewyn / Collé (1714) \\
\hline $\begin{array}{l}\text { abano, ou avano. Flabe- } \\
\text { llum, i. }\end{array}$ & abano: A fan. & $\begin{array}{l}\text { abano, or, avano. Een } \\
\text { waajer. }\end{array}$ \\
\hline $\begin{array}{l}\text { abano de enxotar mos- } \\
\text { cas. Muscarium, i. }\end{array}$ & $\begin{array}{l}\text { abano de enxotar mos- } \\
\text { cas: A flie flap. }\end{array}$ & $\begin{array}{l}\text { abano de enxotar mos- } \\
\text { cas. Eeen waajer, on vlie- } \\
\text { gen te verjaagen. }\end{array}$ \\
\hline abanos. Collaria, ium. & abanos: Collars. & $\begin{array}{l}\text { abanos: halsbanden, } \\
\text { kraagen. }\end{array}$ \\
\hline $\begin{array}{l}\text { abanos da camisa. Pata- } \\
\text { giata, ae... }\end{array}$ & $\begin{array}{l}\text { abanos de camisa: The } \\
\text { gathering of the neck... }\end{array}$ & $\begin{array}{l}\text { abanos de camisa. } \\
\text { Hemds banden... }\end{array}$ \\
\hline
\end{tabular}

Bluteau (1712-1728) foi a fonte de Folqman (1755), de Marquês (17581764), autor do primeiro dicionário português-francês, e de Transtagano (1773), autor do segundo dicionário português-inglês. 


\begin{tabular}{|c|c|c|c|}
\hline Bluteau (1712-1728) & Folqman (1755) & Marques (1758-1764) & Transtagano (1773) \\
\hline $\begin{array}{l}\text { abanar. Agitar, \& } \\
\text { causar vento }[. . .] \text { ven- } \\
\text { tilare... }\end{array}$ & $\begin{array}{l}\text { abanar (causar vento), } \\
\text { ventilare... }\end{array}$ & $\begin{array}{l}\text { abanar (causar vento), } \\
\text { ventilare.... }\end{array}$ & abanar, v. a. to fan. \\
\hline $\begin{array}{l}\text { abanar o fogo: ignem } \\
\text { flabello excitare... }\end{array}$ & $\begin{array}{l}\text { abanar o fogo, ignem } \\
\text { ventilare... }\end{array}$ & $\begin{array}{l}\text { abanar o fogo, ignem } \\
\text { ventilare... }\end{array}$ & $\begin{array}{l}\text { abanar o lume, ou } \\
\text { o fogo, to kindle the } \\
\text { fire... }\end{array}$ \\
\hline $\begin{array}{l}\text { abanar hum arvore: } \\
\text { arborem quatere... }\end{array}$ & $\begin{array}{l}\text { abanar hum arvore, } \\
\text { arborem quatere... }\end{array}$ & $\begin{array}{l}\text { abanar huma arvore, } \\
\text { arborem quatere... }\end{array}$ & $\begin{array}{l}\text { abanar as arvores, to } \\
\text { shake the trees... }\end{array}$ \\
\hline $\begin{array}{l}\text { abanar moscas. Vid. } \\
\text { enxotar. }\end{array}$ & $\begin{array}{l}\text { abanar as moscas, } \\
\text { muscas abigere. }\end{array}$ & $\begin{array}{l}\text { abanar as moscas, } \\
\text { muscas abigere. }\end{array}$ & $\begin{array}{l}\text { abanar as moscas, to } \\
\text { drive the flies away... }\end{array}$ \\
\hline $\begin{array}{l}\text { abanarse. Auram fla- } \\
\text { bello colligere. }\end{array}$ & $\begin{array}{l}\text { abanar-se, aurem fla- } \\
\text { bello colligere... }\end{array}$ & $\begin{array}{l}\text { abanar-se, auram fla- } \\
\text { bello colligere... }\end{array}$ & $\begin{array}{l}\text { abanar-se, to coll } \\
\text { one's self with a fan. }\end{array}$ \\
\hline $\begin{array}{l}\text { abanar as orelhas: } \\
{[\ldots] \text { Surdum simulare. }}\end{array}$ & $\begin{array}{l}\text { abanar as orelhas } \\
{[\ldots] \text {, surdum simulare. }}\end{array}$ & $\begin{array}{l}\text { abanar as orelhas } \\
{[\ldots] \text {, surdum simulare. }}\end{array}$ & $\begin{array}{l}\text { abanar as orelhas, to } \\
\text { give a negative answer. }\end{array}$ \\
\hline
\end{tabular}

Entre os muitos dicionários portugueses que consultei antes de começar o meu projecto existe mesmo um dedicado às ciências naturais, que descreve, entre outros, também os animais. É provável que o autor não tenha tomado obras científicas como base, mas, sim, o dicionário de Bluteau.

É o Diccionario Portuguez das plantas, arbustos, matas, arvores, animaes quadrúpedes, e reptis, aves, peixes, mariscos, insectos, gomas, metaes, terras, mineraes, \&. [...] escrito por José Monteiro de Carvalho (Carvalho 1765). 


\begin{tabular}{|c|c|}
\hline Bluteau (1712-1728) & Carvalho (1765) \\
\hline $\begin{array}{l}\text { Abada, abada }[\ldots] . \text { Fera de Africa nas te- } \\
\text { rras de Benguela }[. . .] \text {, a Abada he hum } \\
\text { animal do tamanho de um potro de } \\
\text { dous annos, com a cabeça mais peque- } \\
\text { na, \& mais chata, que a do cavallo; tem } \\
\text { o pelo denso, \& áspero, rabo de boy, mas } \\
\text { mais curto, \& pés fendidos, muito mais } \\
\text { grossos, que os de veado; tem este ani- } \\
\text { mal dous cornos, hum na testa do com- } \\
\text { primento de três, ou quatro palmos, \& } \\
\text { este negro, ou pardo escuro, lizo, agudo } \\
\text { na ponta [...]. Tem a Abada outro corno } \\
\text { na nuca, mais curto [...], esta ponta da } \\
\text { abada tem fama de contra veneno [...]. O } \\
\text { P. Gaspar Schot [...], \& outros authores } \\
\text { vulgares, como Covarrubias [...] se tem } \\
\text { equivocado [...]. }\end{array}$ & $\begin{array}{l}\text { Abada. Animal quadrúpede, e feroz, que } \\
\text { se cria nas terras de Africa: tem a grande- } \\
\text { za de hum potro de dous annos, o pello } \\
\text { denso, e áspero, rabo de Boi, porém cur- } \\
\text { to, os pés fendidos, e grossos, com duas } \\
\text { pontas: huma na testa de quatro palmos } \\
\text { de comprido, negra, liza, e aguda; outra } \\
\text { na nuca de menor grandeza: qualquer } \\
\text { dellas he singular antídoto para todo o } \\
\text { género de veneno. }\end{array}$ \\
\hline
\end{tabular}

Uma breve anotação entre parêntese: Bluteau é uma das raras excepções à pouca presença portuguesa na dicionarística espanhola.

No primeiro dicionário da Academia espanhola, publicado entre 1726 e 1739, o que chamamos hoje Diccionario de Autoridades, encontramos também Rafael Bluteau. Nos volumes publicados a partir de 1734 achamos citações do dicionário de Bluteau (Gómez-Pablos 2004):

Galardon: El premio, recompensa ò retribucion de los méritos, servicios y beneficios. Bluteau en

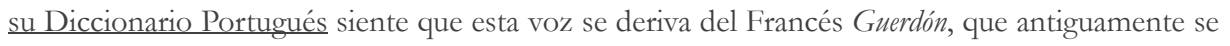
decía Guerredon, esto es don o premio de guerra [segundo Corominas: origen germánico].

Roque: Pieza grande en el juego del Axedrez, que se coloca en la esquinas del tablero. Camina por línea recta, y puede andar de una vez todas sus casas, si las halla desembarazadas de otras piezas. Covarr. dice que significa la fortaleza que se suele hacer al frente de los enemigos: y assi algunos le dan la etymologia de Roca: y Bluteau en su Diccionario Portugues previene, que algunos se la dan de la voz Persa Rokh, que significa caballero errante o aventurero [Corominas: árabe].

Acredito que o Dicionário dos dicionários portugueses vai ser útil muito tempo, porque nem no Brasil nem em Portugal existe algo semelhante ao Corpus diacrónico del español (CORDE) da RAE em Madrid. Existem muitas tentativas de criar corpora, todos pequenos, nenhum projecto de grande envergadura. Se compararmos os resultados já publicados do Corpus informatizado do português medieval (CIPM) da Universidade Nova 
de Lisboa com o Vocabulário do Português medieval, um CD-Rom de António Geraldo da Cunha (2002), constatamos lacunas:

\begin{tabular}{|c|c|c|}
\hline \multicolumn{2}{|c|}{ CIPM (consulta 1.11.2006) } & Cunha (2002) \\
\hline \multirow{2}{*}{\multicolumn{2}{|c|}{$\begin{array}{l}\text { DULDAR cf. DUVIDAR } \\
\text { Ocorrências: } 3\end{array}$}} & \multirow{5}{*}{$\begin{array}{l}\text { duldar (4) vb. Duvidar: sXIII Fuero } \\
\text { Real III.820; S XIV Gen.Estoria 23,1; } \\
\text { Crónica Gen.Gallega 897,50; Hist.Tro- } \\
\text { yana 33.33.; } \\
\text { dultar. (7) vb. Duvidar: sXIII CSM 50.3, } \\
\text { sXIV Crónica Gen.Gallega 98.43; San- } \\
\text { toGraal 119b7; Miragres 225,9; Tristan } \\
\text { 79.3; Hist.Troiana 104.4 Crón.Troyana } \\
\text { 1. 156.6. }\end{array}$} \\
\hline & & \\
\hline C6 & duldariã 1 (Foro real) & \\
\hline $\mathrm{CP} 3$ & dulte 1 (CantigasEsc.Mald.) & \\
\hline PP f.s. & dultada 1 (CEM) & \\
\hline
\end{tabular}

Temos que falar tanto de dicionários portugueses em tanto que fonte de dicionários portugueses, como também de dicionários escritos em outras línguas, a espanhola, sobretudo, e a francesa também, que os lexicógrafos portugueses usaram para redigir as suas obras.

Também temos que distinguir entre dicionários receptores que copiaram inteiramente as entradas do seu modelo, e os outros que só tiraram uma parte do modelo, ou a transformaram.

Com a citação da entrada Compostela, tomada de Bluteau, mostrei que o Covarrubias (1611), chamado por Bluteau "curioso investigador de etimologias", era uma fonte importante para explicar a etimologia de palavras portuguesas em 1700, mas nem sempre Bluteau aceitou cegamente o que escreveu Covarrubias. Por isso reproduço uma parte da entrada Abada:

O P. Gaspar Schot [...], \& outros authores vulgares, como Covarrubias [...] se tem equivocado.

Covarrubias foi também a fonte para difundir as explicações etimológicas em Portugal que o Padre Guadix já redigiu antes de 1593 (Guadix 1593; cfr. Messner 2007a).

O seguinte exemplo, que ilustra a prolongada influência de Covarrubias em Portugal, provém do Dicionário da Academia Portuguesa, publicado em 1793: 


\begin{tabular}{|c|c|}
\hline Academia das Ciências (1793) & Covarrubias (1611) \\
\hline $\begin{array}{l}\text { Alquitira. s. f. Certo arbusto de flores } \\
\text { polypetalas, e da familia das leguminosas. } \\
\text { He denominada por Linneo Astragalus } \\
\text { tragacantha. He hum arbusto pequeno, } \\
\text { espinhoso, que nasce frequentemente na } \\
\text { Asia, nas vizinhanças de Alepo, em Can- } \\
\text { dia, e outras mais partes [...]. } \\
\text { He voz puramente Arabiga, segundo } \\
\text { Covarrubias, que traz as origens, que lhe } \\
\text { assignão Diogo de Urréa e o P. Guadix. } \\
\text { A. da Cruz, Recop. } 2,8 \text { Fação este cole- } \\
\text { rio. R. Sarcaiola nutrida [...] alquitira, \&c. } \\
\text { Azev. Correcç. 2,2,121 Alquitira e gom- } \\
\text { ma arabiga. Morat. Pratic. 1,30,1 Gomma } \\
\text { alcatira, amendoas doces, de cada hum } \\
\text { meia onça. }\end{array}$ & $\begin{array}{l}\text { Alquitira. Es cierto género de goma que } \\
\text { distila una planta dicha [...] tragacantha, } \\
\text { id est, hircispinae; nace ordinariamente } \\
\text { en Arcádia y en Creta y en el Peloponeso; } \\
\text { descríbela Dioscórides, lib. 3, cap. 21; y } \\
\text { por esta razón Ant. Neb. vuelve dragan- } \\
\text { tum. Los médicos la llaman gummi dragan- } \\
\text { tina, los arábigos alquitira; y dice Diego de } \\
\text { Urrea que se dijo así del verbo cathare, } \\
\text { que sinifica distilar, porque es gota que } \\
\text { se distila del dicho árbol. Paréceme que } \\
\text { le da la mesma raiz que dio a alquitara. } \\
\text { El padre Guadix dice haberse dicho al- } \\
\text { quitara de quitir, que vale mucho, porque } \\
\text { echada en agua poça cantidad della se } \\
\text { extiende y se hace mucho. }\end{array}$ \\
\hline
\end{tabular}

Quando encontrei esta palavra no dicionário português de 1793 perguntei-me, por quê é que, pouco antes do ano de 1800, os lexicógrafos académicos copiaram o resumo que Covarrubias fez das duas etimologias propostas, uma pelo Padre Guadix, do que o livro recebeu a licença em 1593, quer dizer já 200 anos antes da publicação do dicionário português de 1793, e a outra por Diego de Urrea, uma autoridade -parece- ao redor de 1600, porque é nomeado por Covarrubias no prólogo ao leitor assim: "Yo he consultado a Diego de Urrea, intérprete del rey nuestro señor".

Os dicionários portugueses posteriores são mais explícitos:

Alquitira ou Alcatira, s. f. (do Arab. alcatira, derivado do verbo cátara, pingar, destillar, gottejar, porque a gomma alcatira ou tragacantho transsuda da planta), a gomma tragacantho; it. a planta que a dá (astragalus tragacantha) (Constâncio 1836).

Ponho ao lado do dicionário de 1845 a entrada do de 1793: 


\begin{tabular}{|c|c|}
\hline Diccionario Universal (1845) & Academia das Ciências (1793) \\
\hline $\begin{array}{l}\text { Alquetira, (ant.) V. Alquitira. } \\
\text { Alquitira, s. f. (bot.) Arbusto de flores } \\
\text { polypétalas, e da familia das legumino- } \\
\text { sas, denominada por Linneo astragalus } \\
\text { tragacantha. É pequeno e espinhoso; dá } \\
\text { umas flores purpurinas, ás quaes succe- } \\
\text { dem bainhas villosas, inchadas, e cheias } \\
\text { de pequenos grãos da figura de um rim. } \\
\underline{\text { Do tronco e ramos d'esta planta, corre }} \\
\text { naturalmente, ou por incisões que se fa- } \\
\text { zem, um succo gommoso (draganthum } \\
\text { gummi) branco ou cinzento, luzidio, } \\
\text { leve, sem gosto nem cheiro, que tambem } \\
\text { se chama alquitira. Quando se lança de } \\
\text { infusão em agua, incha muito, e parece } \\
\text { uma especie de creme gelado. Esta mu- } \\
\text { cilagem de gomma alquitira emprega-se } \\
\text { na pharmacia, e serve para outros usos. } \int \\
\text { arab. alcatira; do v. cátara, pingar, distillar, } \\
\text { gottejar; porque a gomma alcatira, ou tra- } \\
\text { gacantho transsuda da planta. }\end{array}$ & 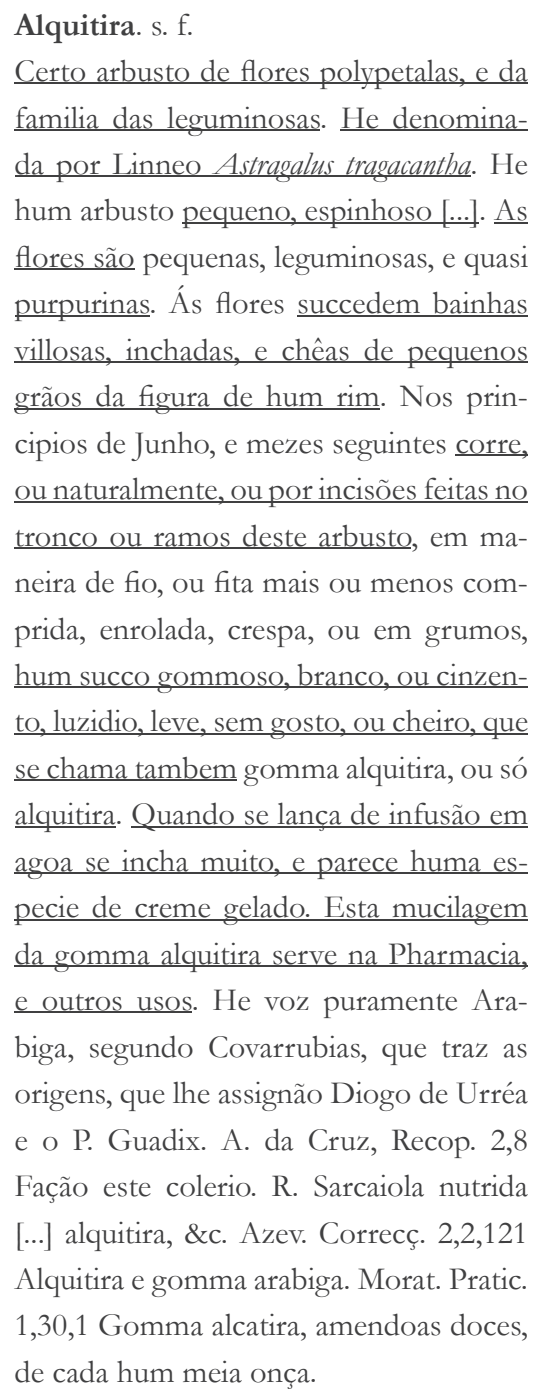 \\
\hline
\end{tabular}

Alquitíra, s. f. (do Arab. alcatira) Herva, e juntamente gomma medicinal. (Dragacanthum gummi). Morat. Prat. 1. 30. 1. S. Alguns dizem alquetiro (Morais 1858 ${ }^{\circ}$ ).

Alquitira, s. f. (Do árabe alcatira) O mesmo que Alcatira [...] (Vieira 1871-1874).

Alcatira s. f. ant. (Do árabe alcatira; do verbo catara, pingar, distillar.) Arbusto de flores polypétalas, da família das leguminosas. Produz um succo gommoso, branco, cinzento, inodoro e insípido; é uma mucilagem empregada na Pharmacia [...] (Vieira 1871-1874).

Constâncio deve ter conhecido também o dicionário de Covarrubias, porque o seu texto se parece muito ao de Covarrubias. Foi copiado pelos lexicógrafos do Diccionario Universal (1845), no qual o resto da microestrutura provém do dicionário académico de 1793 (isso fez também Domingos Vieira). 
Os académicos portugueses de 1793 foram prudentes. Fizeram bem porque algumas explicações são extravagantes. Guadix, por exemplo, deduz o nome da capital da Áustria, Viena, de elementos árabes. Os académicos portugueses não transcrevem as duas propostas etimológicas de Covarrubias, porque não souberam qual a melhor entre as duas. Já tiveram entre mãos uma obra, os Vestígios da Língua Arábica em Portugal, ou lexicon etymologico das palavras, e nomes portuguezes, que tem origem arábica (Sousa 1789). Muitas vezes aproveitam dela, mas na edição de 1789 a palavra alquitira ainda não está; por isso foram forçados a recorrer a Covarrubias, sem meterse nas explicações divergentes entre Urrea e Guadix.

De onde é que vem então a frase "derivado do verbo cátara 'pingar, distillar"'? Constâncio (1836) copiou a explicação etimológica da palavra alcatrão que está em Sousa (1789), porque este deduz alcatrão do verbo árabe cátara; verbo que está em Covarrubias e que provém de Urrea:

Alcatrão [...] Alcatrán. Espécie de bitume liquido. Deriva-se do verbo cátara pingar, distillar, cahir ás pingas; porque o pez se colhe das gotas da resina, que o pinheiro de si distilla (Sousa 1789).

Na nova edição do mesmo livro sobre Vestígios arábigos, feita em Lisboa em 1830, já está alquitira com o étimo:

Alquitira [...] Arab. Alcatira. He nome de certo arbusto, ou da goma de certa raiz (Sousa / Moura 1830).

Por isso, os redactores do Morais (1858 $)$ cópiam esta explicação e não reproduzem aquela do Diccionario Universal (1845).

Vemos então, graças a estes exemplos que são muitos os dicionários espanhóis que serviam de fonte aos antigos dicionários portugueses.

É interessante constatar que ainda hoje, os dicionários portugueses modernos recorrem a fontes espanholas para explicações etimológicas de palavras portuguesas.

Comparei os comentários etimológicos sobre a palavra chinela em sete dicionários portugueses modernos (Messner 2007b), e constatei que existe uma semelhança textual bastante grande entre as explicações etimológicas dos dicionários citados.

A solução do enigma é que todos os lexicógrafos portugueses citados copiaram o que foi escrito, bastantes anos antes, pelo lexicógrafo espanhol Joan Corominas (1954-1957) no Diccionario crítico etimológico de la lengua castellana, texto retomado letra por letra na edição de 1980. 
Como já disse antes, a minha especialidade é a dicionarística histórica da língua portuguesa: por isso vou servir-me de exemplos tirados do meu Dicionário dos dicionários portugueses, para ilustrar a minha contribuição.

Já mencionei o facto de existirem dicionários que copiavam por inteiro o que está em outros dicionários. Um exemplo: um dos dicionários portugueses que contem microestruturas que diferem de maneira vistosa das definições contidas em dicionários anteriores é o Diccionario da Lingoa Portugueza publicado pela Academia Real das Sciencias de Lisboa (Academia das Ciências 1793), que só contém a letra A, um dicionário já mencionado antes, quando falei do arabista espanhol Guadix.

Por um lado encontramos no dicionário académico muitas descripções científicas de plantas e animais (já o vimos na entrada alquitira, onde aparece uma informação moderníssima, a do botânico Linneo, ao lado de uma etimologia proposta 200 anos antes):

\footnotetext{
agoa [...]. As agoas naturaes destilladas sáo tambem do numero das artificiaes, estas, e as da chuva sáo as mais puras, que se conhecem, e no seu pezo especifico sáo para a agoa do mar :: 10000 : 10263; sáo para o ouro :: $1: 19114$ e sáo para o ar :: $800: 1$; estando o barometro em 28 pollegadas, e o thermometro de Reaumur em 14112 gráos [...].
}

Pelo outro lado há definições de palavras triviais, que diferem das dos dicionários anteriores, e em terceiro lugar há microestruturas não acompanhadas de textos reais.

Esta falta de ilustrações contrasta com uma frase do prólogo, onde podemos ler:

O Diccionario [...] deverá conter os vocabulos puramente Portuguezes em todas as suas significações [...] inteiramente com o uso regular [...] fixado tudo pelos exemplos dos Autores Classicos.

A discrepância entre a metodologia proposta no prólogo e a realidade tal qual a encontramos nas entradas conduz-me a comparar o dicionário académico português com obras estrangeiras, também com a da Academia espanhola, o chamado Diccionario usual (RAE 1780).

Não é dificil ver que nas microestruturas de muitas entradas as definições portuguesas e espanholas são semelhantes, o que não pode ser um puro acaso. 


\begin{tabular}{|c|c|}
\hline RAE (1780) & Academia das Ciências (1793) \\
\hline $\begin{array}{l}\text { Ala. Mil. La parte de tropa que cubre el } \\
\text { centro del exército por qualquiera de los } \\
\text { dos costados (p. 36). }\end{array}$ & $\begin{array}{l}\text { Ala Milic. A parte da tropa, que cobre o } \\
\text { centro do exercito por qualquer dos dous } \\
\text { costados (p. 178). }\end{array}$ \\
\hline $\begin{array}{l}\text { Alcanzadura s. f. Alb. La hinchazon que } \\
\text { suele hacerse a las caballerías de algun } \\
\text { golpe de hierro, ó piedra en la parte trase- } \\
\text { ra del pie junto á la uña, ó casco. Llámase } \\
\text { tambien así la contusión, ó herida que se } \\
\text { les hace topándose el pie con la mano } \\
{[\ldots . .] \text { (p. 44) [= Diccionario de Autoridades, }} \\
\left.1770^{2}, 148\right] \text {. }\end{array}$ & $\begin{array}{l}\text { Alcançadura, s. f. Alveit. Inchação, que } \\
\text { se costuma fazer nas cavalgaduras por al- } \\
\text { gum golpe de ferro o de pedra na parte } \\
\text { posterior do pé junto á unha ou casco; ou } \\
\text { tambem a contusão ou ferida, que ellas } \\
\text { mesmas se fazem a si, tocandose com a } \\
\text { ferradura do pé na mão [...] (p. 190). }\end{array}$ \\
\hline $\begin{array}{l}\text { Algo s. m. ant. Bienes, hacienda, caudal; } \\
\text { en este sentido se usó también antigua- } \\
\text { mente en número plural (p. } 50 \text { ) }\end{array}$ & $\begin{array}{l}\text { Algo s. m. antiq. Fazenda, haver, cabedal, } \\
\text { bens. Tambem se usa neste sentido no } \\
\text { plural (p. 212). }\end{array}$ \\
\hline
\end{tabular}

Alguns colegas atribuem certa importância ao primeiro e único volume de este dicionário:

Em suma, verifica-se que o $1 .^{\circ}$ Dicionário da Academia é ainda hoje um modelo de técnica lexicográfica, elaborado com o maior rigor científico [...] (Casteleiro 1993: XXII).

Eu acho que este dicionário, visto sob uma perspectiva moderna, não merece estes elógios.

De vez em quando os três lexicógrafos citam de maneira explícita o dicionário castelhano da RAE.

$\mathrm{Na}$ entrada alcorque podemos ler:

\begin{tabular}{|c|c|c|}
\hline $\begin{array}{c}\text { Academia das Ciências } \\
\text { (1793) }\end{array}$ & $\begin{array}{l}\text { Diccionario de Autori- } \\
\text { dades (1770) }\end{array}$ & RAE (1780) \\
\hline $\begin{array}{l}\text { Alcorque. s. m. ant. Certo } \\
\text { calçado antigo, que tinha a } \\
\text { sola de cortiça. No Diccion. } \\
\text { Castelhano se diz, que pare- } \\
\text { ce vir do Arabigo córque, } \\
\text { que significa o mesmo, } \\
\text { accrescentado o articulo } \\
\text { al [...]. }\end{array}$ & $\begin{array}{l}\text { Alcorque, s. m. antiq. Za- } \\
\text { pato ú outro calzado, que } \\
\text { tenia la suela de corcho. } \\
\text { Parece viene del árabe } \\
\text { corque, que significa lo } \\
\text { mismo añadido el artículo } \\
\text { al }[\ldots] \text {. }\end{array}$ & $\begin{array}{l}\text { Alcorque, s. m. antiq. Za- } \\
\text { pato, ú outro calzado, que } \\
\text { tenía la suela de corcho. } \\
\text { Parece viene del árabe } \\
\text { corque, que significa lo } \\
\text { mismo añadido el artículo } \\
\text { al [...]. }\end{array}$ \\
\hline
\end{tabular}


O mesmo dicionário da Academia Portuguesa serviu-se também de uma obra fundamental francesa, a Encyclopédie (1752), traduzindo-a e reorganizando a estrutura interna das entradas, sem indicar, claro, a fonte, que foi, naquela época, proibida em Portugal. A numeração é minha:

Encyclopédie 1752, vol. I. 363ss.

Ammoniac, sel Ammoniac ou Armoniac, sal ammoniacus seu armeniacus (Hist. nat.)

[1] Nous ne connoissons le sel ammoniac des anciens que par les descriptions quils en ont laissé: autant que nous pouvons en juger aujourdhui, il paroît que ce sel étoit assez semblable à notre sel gemme.

[2] Les anciens lui ont donné le nom de sel ammoniac, parce qu'on le trouvait en Libye aux environs du temple de JupiterAmon.

[3] Quelques-uns l'ont appellé sel armoniac, ou armeniac, peut-être à cause du voisinage de l'Armenie ...

[4] Nous connoissons aujourd'hui deux sortes de sel ammoniac, le naturel \& le factice. Le sel ammoniac naturel se tire des soufrieres de Pouzzol, dans cette grande fosse...

Il y a des fentes dans quelques endroits, d'où l'on voit sortir la fumée le jour \& des flammes la nuit. On entasse sur ces fentes des monceaux de pierres; les évaporations salines qui sont continuellement élevées pare les feux soûterrains, passent à travers ces monceaux, \& laissent sur les pierres une suie blanche, qui forme après quelques jours une croûte de sel ...

[5] M. d'Herbelot rapporte dans sa

Bibliothéque orientale que dans le petit pays de Boton en Asie, ... ... que les habitans du pays appellent nuschader.

[6] ... Le Sel ammoniac, si l'on en croit l'illustre Boerhaave, garantit toutes les substances animales de la corruption....
Dicionário português 1793, 276.

Ammoniaco adj. (Sal) Certa especie de Sal.

[2] He denominado pelos antigos sal almoniaceum ou armoneacum, e armenium, ou porque se achava nas vizinhanças do templo de Jupiter Ammon na Lybia,

[3] ou porque os lugares, em que se encontrava erão proximos a Armenia.

[1] As descripções, que os Antigos nos deixarão, deste sal o fazem semelhante ao nosso sal gemma.

[4] Presentemente distinguem-se duas especies de sal ammoniaco, natural, e artificial. O natural se extrahe, principalmente das minas de enxofre do Pouzzol, aonde

sobre as fendas, de que de dia se vê sahir fumo, e de noite chammas, se atravessão pedaços de pedras, por entre as quaes passando as evaporaçôes salinas das minas, deixão em cima das pedras huma ferrugem branca, que alguns dias depois fórma humas crustas de sal, ...

[5] Segundo Herbelot hao tambem no paiz de Botom na Asia,...

... Os naturaes the chamão Muschader ...

[6] ... Boerhaave o julga accommodado para preservar todas as substancias animaes de corrupção ... 
Mais interessante e provavelmente não conhecida é a influência espanhola sobre os dicionários posteriores em Portugal, no século XIX, no que as grandes línguas europeias criaram os seus dicionários.

Os três lexicógrafos académicos de 1793 não foram os únicos em traduzir dicionários espanhóis, sem declará-lo. Em 1806 publicou-se o Novo Diccionario da Lingua Portugueza, composto sobre os que até ao presente se tem dado ao prelo, e Accrescentado de varios vocabulos extrahidos dos Classicos Antigos, e dos Modernos de melhor nota, que se achaõ universalmente recibidos (Novo Diccionario 1806).

É notória a inserção de muitos neologismos recuperados -dizem- no título de autores portugueses antigos e modernos. A verdade é por completo outra: encontrei as palavras também no Diccionario castellano con las voces de ciencias y artes y sus correspondientes en las tres lenguas Francesa, Latina é Italiana, de Esteban de Terreros y Pando (Terreros 1786).

\begin{tabular}{|c|l|l|}
\hline Terreros (1786) & \multicolumn{1}{|c|}{$\begin{array}{c}\text { Novo Diccionario } \\
\text { (1806) }\end{array}$} & $\begin{array}{c}\text { Diccionario Universal } \\
\text { (1845) }\end{array}$ \\
\hline $\begin{array}{l}\text { Alioth, termino de As- } \\
\text { tronomia, nombre de una } \\
\text { estrella que está en la cola } \\
\text { de la Osa mayor; sirve para } \\
\text { conocer la altura del Polo. }\end{array}$ & $\begin{array}{l}\text { Allioth, s. m. Estrella da } \\
\text { cauda da ursa maior. }\end{array}$ & $\begin{array}{l}\text { Allioth, s. m. (ast.) Estre- } \\
\text { lla na cauda da ursa-maior, } \\
\text { que se observa no mar } \\
\text { para se conhecer a altura } \\
\text { do polo. }\end{array}$ \\
\hline
\end{tabular}

É possível que os redactores do dicionário universal de 1845 tenham copiado também o Terreros y Pando, visto a semelhança textual:

\begin{tabular}{|l|l|l|}
\hline \multicolumn{1}{|c|}{ Terreros (1786) } & $\begin{array}{c}\text { Novo Diccionario } \\
\text { (1806) }\end{array}$ & $\begin{array}{c}\text { Diccionario Universal } \\
\text { (1845) }\end{array}$ \\
\hline $\begin{array}{l}\text { Alibanias, ciertas telas } \\
\text { de algodon, que trahen } \\
\text { de las Indias Orientales á } \\
\text { Holanda. }\end{array}$ & $\begin{array}{l}\text { Alibania s. f. Estofo das } \\
\text { Indias Orientaes. }\end{array}$ & $\begin{array}{l}\text { Alibania, s. f. (Com.) Pan- } \\
\text { no de algodão da India. }\end{array}$ \\
\hline
\end{tabular}

É possível que os redactores do dicionário de 1818 copiassem também o Terreros y Pando, visto a palavra algodão.

Também o Morais copiou de uma obra, do Viterbo (1798-1799). Na segunda edição de Morais, de 1813, aparecem os mais raros arcaísmos, alguns deles hapaxlegomena em dicionários portugueses do século XIX, se 
bem que Morais argumenta, no "Prólogo do autor à primeira impressão", de 1813: "Os Autores, com que autorizei os Artigos addidos, são Portuguezes castiços [...]”. Um exemplo:

Ousám. Atrevimento, insolencia, desaforo. Vem do Latino Audeo (Viterbo 1798-1799).

Ousão, s. m. antiq. Atrevimento. Elucidar (Morais 1813).

Ousão, s. f. (ant.) Atrevimento (Diccionario Geral 1818).

Ousão, s. m. antiq. Atrevimento. Elucidar (Morais 1831).

Ousão s. obsol. V. Atrevimento, Ousadia (Constâncio 1836).

Ousão, s.m.ant. Atrevimento. Eluc. (Morais 1858).

Ousão, s. m. Termo antiquado. Audacia, arrojo, atrevimento (Vieira 1871-1874).

É uma palavra para a qual nem Viterbo reproduz o documento, mas com a entrada no Morais de 1813 e a sua autoridade obteve direito à vida e perpetuou-se em todos os dicionários seguintes.

Ter-me-ia sido possível enumerar muitos mais exemplos para indicar a dependência de dicionários portugueses de outros, portugueses e estrangeiros, que lhes antecedem, mas, acredito, os exemplos com o que ilustrei a minha contribuição são suficientes. 


\section{ANEXO}

1. Coloquio de Lexicografía (Instituto da Lingua Galega, Santiago de Compostela, 27 de febreiro - 1 de marzo de 1986).

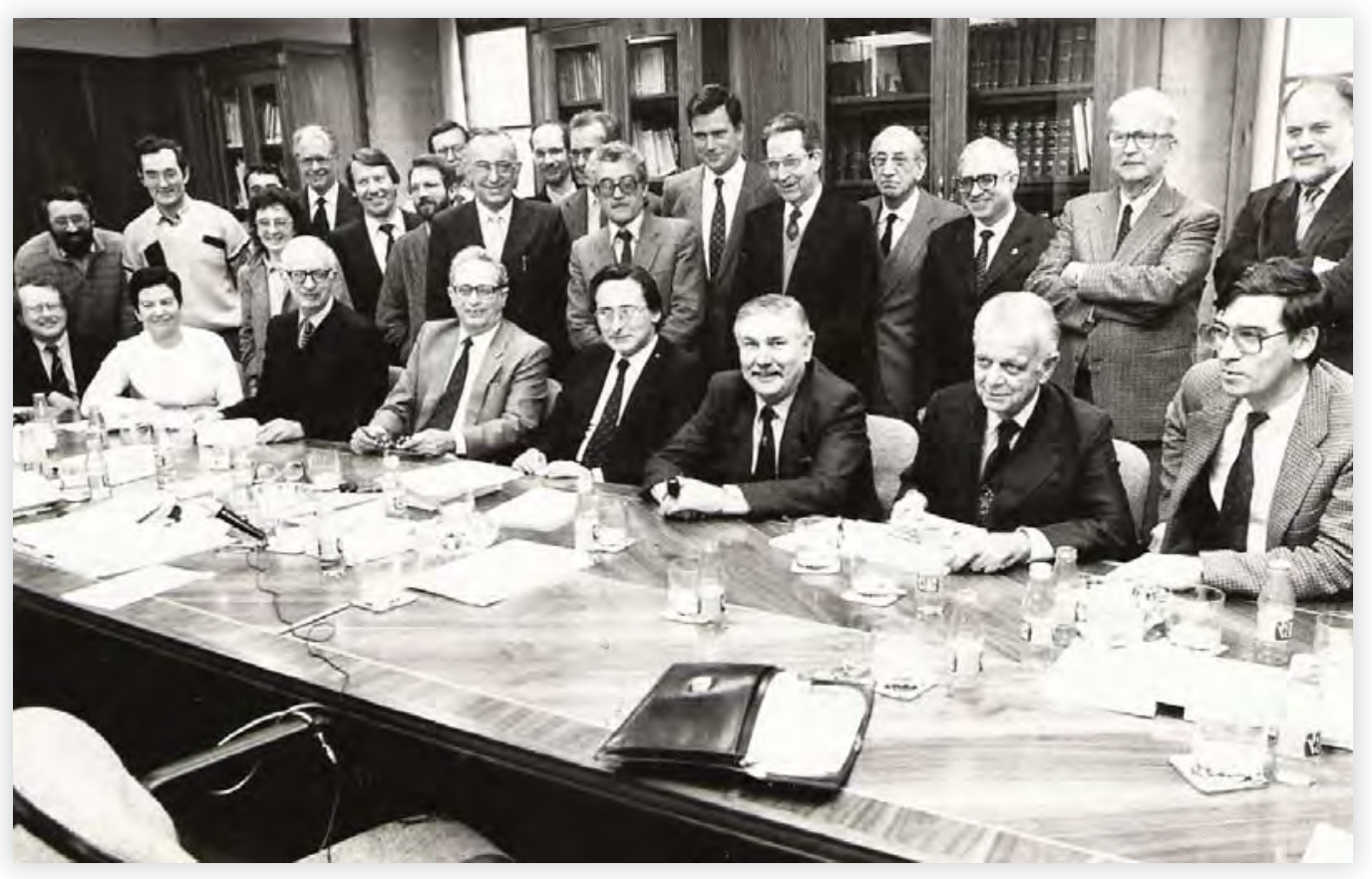

